\title{
Rates of Processing Determine the Immunogenicity of Immunoproteasome-Generated Epitopes ${ }^{1}$
}

\author{
Parampal Deol, ${ }^{2 *}$ Dietmar M. W. Zaiss, ${ }^{2 *}$ John J. Monaco, ${ }^{\dagger}$ and Alice J. A. M. Sijts ${ }^{3 \dagger}$
}

CD8 $\mathrm{T}$ cells resolve intracellular pathogens by responding to pathogen-derived peptides that are presented on the cell surface by MHC class I molecules. Although most pathogens encode a large variety of antigenic peptides, protective CD8 T cell responses target usually only a few of these. To determine the mechanism by which the IFN- $\gamma$-inducible proteasome (immuno) subunits enhance the ability of specific pathogen-derived peptides to elicit CD8 $\mathbf{T}$ cell responses, we generated a recombinant Listeria monocytogenes strain (rLM-E1) that secretes a model Ag encompassing the immunoproteasome-dependent E1B 192-200 $_{\text {and }}$ immunoproteasome-independent E1 $\mathbf{A}_{234-243}$ epitope. Analyses of Ag presentation showed that infected gene-deficient professional APCs, lacking the immunosubunits $L M P 7 / i \beta 5$ and $M E C L-1 / i \beta 2$, processed and presented the rLM-E1-derived E1B $_{192-200}$ epitope but with delayed kinetics. E1A epitope processing proceeded normally in these cells. Accordingly, infected gene-deficient mice failed to respond to the otherwise immunodominant E1B $_{192-200}$ epitope but mounted normal CD8 $T$ cell responses to $\mathrm{E}_{1 \mathrm{~A}_{234-243}}$ which was processed by the same professional APCs, from the same rLM-E1 Ag. The inability of gene-deficient mice to respond to $\mathrm{E}_{1} \mathrm{~B}_{192-200}$ was not explained by insufficient quantities of antigenic peptide, as splenic $\mathrm{APC}$ of 36-h-infected gene-deficient mice that presented the two E1 epitopes at steady state levels elicited responses to both $\mathbf{E}_{1} \mathrm{~B}_{192-200}$ and $\mathrm{E}_{1 \mathrm{~A}_{234-243}}$ when transferred into $L M P 7+M E C L-1$-deficient mice. Taken together, our findings indicate that not absolute epitope quantities but early Ag-processing kinetics determine the ability of pathogen-derived peptides to elicit CD8 $T$ cell responses, which is of importance for rational $T$ cell vaccine design. The Journal of Immunology, 2007, 178: 7557-7562.

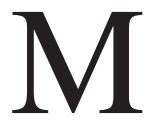

ost intracellular pathogen-derived proteins are degraded by host cell proteasomes, leading to the generation of antigenic peptides that associate with MHC class I molecules for presentation on the cell surface to surveilling CD8 T cells. It is well established that a variety of selective processes operating at the Ag processing and $\mathrm{T}$ cell levels limit the diversity of CD8 $\mathrm{T}$ cell responses mounted by the infected host $(1,2)$. For example, antigenic peptides must be liberated from their protein context, must be transported into the endoplasmic reticulum and must bind MHC class I molecules with high affinity. On the $\mathrm{T}$ cell site, precursors capable of recognizing the MHC-peptide combination must exist. Nevertheless, although multiple pathogen-derived peptides fulfill these criteria, only a few peptides are recognized during the acute phase of infection, suggesting that additional, thus far poorly understood, determinants influence the ability of single epitopes to dominate the CD8 $\mathrm{T}$ cell response.

Generation of most MHC class I-presented antigenic peptides requires proteasome activity. In infected tissues and professional

*D. Smith Center for Vaccine Biology and Immunology and Department of Microbiology and Immunology, University of Rochester, Rochester, NY 14642; and Department of Molecular Genetics, University of Cincinnati, Cincinnati, OH 45267

Received for publication January 10, 2007. Accepted for publication January $10,2007$.

The costs of publication of this article were defrayed in part by the payment of page charges. This article must therefore be hereby marked advertisement in accordance with 18 U.S.C. Section 1734 solely to indicate this fact.

${ }^{1}$ This work was supported by the Howard Hughes Biomedical Research Support Program for Medical Schools and National Institutes of Health Grant AI064576 (to A.S.) and by the German Research Council (DFG Za 280 to D.Z.).

${ }^{2}$ P.D. and D.M.W.Z. contributed equally to this work.

${ }^{3}$ Address correspondence and reprint requests to Dr. A. Sijts, Department of Infectious Diseases and Immunology, Faculty of Veterinary Medicine, University of Utrecht, Utrecht, The Netherlands. E-mail address: E.J.A.M.Sijts@ vet.uu.nl
APCs (pAPC), ${ }^{4}$ the constitutive catalytic proteasome subunits are replaced by three cytokine-inducible homologs (LMP2/induced (i) $\beta 1$, multicatalytic endopeptidase complex-like-1 (MECL-1)/i $\beta 2$ and LMP7/i $\beta 5$ ), resulting in the formation of so-called immunoproteasomes (3). Analyzing the products generated upon proteasome-mediated digestion of polypeptide substrates, we and others have found that the incorporation of the inducible subunits alters the cleavage preferences of proteasomes and accelerates the generation of a subset of CD8 T cell epitopes, which often dominate the pathogen-specific CD8 T cell response (4, 5). Nevertheless, immunosubunit incorporation mainly influences the frequency with which specific cleavage sites are used. Thus, immunoproteasomes generate specific epitopes rapidly and in high quantities; nevertheless, in many cases constitutive proteasomes excise the same epitopes when given enough time.

Because immunosubunit incorporation often does not lead to new peptide species, the reasons for the observed immunodominance of immunoproteasome-generated peptides are unclear. On the one hand, efficient immunoproteasome-mediated peptide liberation enhances the absolute densities of such peptides on priming pAPCs, possibly raising these over the threshold levels for CD8 T cell priming. In contrast, peptides that are efficiently processed will be the first to be presented on pAPCs with priming capacity. Such peptides may be more likely to be detected by Ag-specific naive T cells than peptides that are presented at a later time point, although by the same pAPC. In support of the last hypothesis, Willis et al. (6) recently showed that competition between CD8 T cells of different specificities for binding to the same dendritic cell (DC) is a

\footnotetext{
${ }^{4}$ Abbreviations used in this paper: BM, bone marrow; DC, dendritic cell; LMP, low-molecular-mass polypeptide; MECL-1, multicatalytic endopeptidase complexlike-1; pAPC, professional APC; rLM, recombinant Listeria monocytogenes; i, induced.
}

Copyright $@ 2007$ by The American Association of Immunologists, Inc. 0022-1767/07/\$2.00 
very early event in $\mathrm{T}$ cell activation and restricts the number of $\mathrm{T}$ cells entering the response.

To determine whether the enhanced rate of processing and, consequently, a rapid presentation of immunoproteasome-dependent epitopes $(4,7)$ contributes to immunodominance, we have set up a well-controlled infection model in which previously defined immunoproteasome-dependent and independent epitopes are processed from the same Ag. This Ag is synthesized and secreted by the intracellular bacterium Listeria monocytogenes, excluding a role for defective ribosomal initiation products as a source of Ag in infected cells. Thus, in both infected cells and crosspresenting pAPCs, only mature, secreted bacterial Ags will enter the Ag-processing pathway. Processing of and CD8 T cell responses to different immunoproteasome-dependent and independent epitopes were analyzed in mice lacking the immunosubunits $L M P 7 / i \beta 5$ and $M E C L-1 / i \beta 2$ and compared with those in normal mice.

\section{Materials and Methods \\ Mice and infections}

Recombinant L. monocytogenes (rLM)-OVA (8) and rLM-E1 were grown in brain-heart infusion medium (BD Biosciences), supplemented with 5 $\mu \mathrm{g} / \mathrm{ml}$ erythromycin and $250 \mu \mathrm{g} / \mathrm{ml}$ spectinomycin, respectively, and harvested while in log phase. C57BL/6 (B6) mice were purchased from The Jackson Laboratory. $L M P 7+M E C L-1$ double-gene-deficient B6 mice (9) were maintained by in-house breeding under standard conditions. For primary infection, 6- to 12-wk-old female mice were inoculated i.v. into the tail vein with $0.1 \times \mathrm{LD}_{50} \mathrm{rLM}\left(5 \times 10^{3} \mathrm{rLM}-\mathrm{E} 1\right.$ or $\left.1 \times 10^{5} \mathrm{rLM}-\mathrm{OVA}\right)$ in $100 \mu \mathrm{l}$ of PBS. Reinfection was performed 28-30 days later with 100-fold higher bacterial doses. All experiments involving animals were approved by the Institutional Committee on Animal Resources of the University of Rochester Medical Center (Rochester, NY).

\section{Cell lines}

EL4 and ANA-1 cells were cultured in RPMI (Invitrogen) and RMA-S cells in IMDM (Invitrogen Life Technologies), supplemented with $10 \%$ FCS (HyClone Laboratories), $2 \mathrm{mM}$ L-glutamine, $30 \mu \mathrm{M} 2-\mathrm{ME}$, and

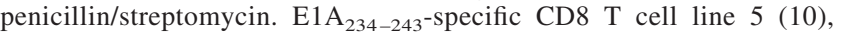

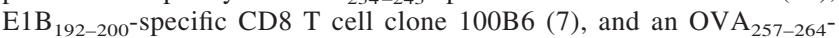
specific CD8 $\mathrm{T}$ cell line (generated from the spleen of an rLM-OVAinfected B6 mouse) were cultured in IMDM containing $0.5 \mathrm{ng} / \mathrm{ml} \mathrm{hu-}$ man recombinant IL-2 (NCI Biological Resources Branch) and 50 $\mu \mathrm{g} / \mathrm{ml}$ gentamicin and maintained by weekly restimulation with irradiated, peptide-pulsed LPS blasts. After five restimulations, $100 \%$ of $\mathrm{OVA}_{257-264}$-stimulated T cells expressed CD8 and were Ag specific.

\section{Class I stability}

RMA-S cells, lacking the TAP transporter, were seeded in the wells of 24-well plates at a concentration of $10^{6}$ cells $/ \mathrm{ml}(1 \mathrm{ml} / \mathrm{well})$ in protein-free hybridoma medium (Invitrogen Life Technologies). Cells were incubated with $60 \mu \mathrm{M}$ synthetic $\mathrm{E}_{1} \mathrm{~A}_{234-243}, \mathrm{E}_{1 \mathrm{~B}_{192-200}}$ (both from Invitrogen Life Technologies) or without peptide at $37^{\circ} \mathrm{C}$ overnight and then harvested, washed three times with PBS, and chased at $37^{\circ} \mathrm{C}$ in the absence of peptide. Samples were taken after 0,2, 4, and $6 \mathrm{~h}$; washed with ice-cold PBS with $1 \%$ BSA and $0.02 \% \mathrm{NaN}_{3}$; and stained for $\mathrm{H}_{2}-\mathrm{D}^{\mathrm{b}}$ or $\mathrm{H} 2-\mathrm{K}^{\mathrm{b}}$ class I expression with biotin-conjugated mouse mAbs (28.14.8 and AF6-88.5 respectively) and PE-conjugated SA (eBioscience). Cells were analyzed on a FACSCalibur (BD Biosciences), using CellQuest software. Mean fluorescence levels detected on peptide-pulsed cells were corrected for the background levels, detected on cells that had been incubated minus peptide, and then used to determine MHC-peptide complex half-lives.

\section{Intracellular cytokine staining}

Approximately $10 \times 10^{6}$ erythrocyte-depleted splenocytes were incubated for $6 \mathrm{~h}$ with or without $500 \mathrm{nM}$ synthetic peptide, in $1 \mathrm{ml}$ of RPMI 1640 medium containing $50 \mu \mathrm{g} / \mathrm{ml}$ gentamicin and $9 \mu \mathrm{M}$ monensin (eBioscience). Thereafter, cells were stained with an FITC-conjugated anti-mouse $\mathrm{CD} 8 \mathrm{Ab}$ (clone 53-6.7; eBioscience) in the presence of antiCD16/32 (clone 2.4G2; eBioscience), fixed with $2 \%$ paraformaldehyde, and then stained with XMG1.2-PE (anti-IFN- $\gamma$; eBioscience) in the presence of $0.5 \%$ saponin. Cells were analyzed on a FACSCalibur.

\section{IFN- $\gamma$-ELISPOT}

Ninety-six-well MAIP ELISPOT plates (Millipore) were coated with 2 $\mu \mathrm{g} / \mathrm{ml}$ AN18 (anti-mouse IFN- $\gamma$ ) in $100 \mu \mathrm{l}$ of PBS for at least $2 \mathrm{~h}$ at room temperature. Wells were then washed and blocked twice with RPMI 1640 medium. EL4 cells were pulsed with or without synthetic peptide $(2 \mu \mathrm{M})$ for 2-3 $\mathrm{h}$ and then washed. Splenocyte dilutions, starting with $1 \times 10^{6}$ cells/well, were coincubated overnight with $3 \times 10^{4}$ unpulsed or peptidepulsed EL4 cells in $100 \mu \mathrm{l}$ of IMDM-medium with gentamicin. Thereafter, the plates were washed with PBS plus $0.01 \%$ Tween 20 (PBST), and IFN- $\gamma$ was detected by incubation with $2 \mu \mathrm{g} / \mathrm{ml}$ biotinylated XMG1.2, followed by $1 \mu \mathrm{g} / \mathrm{ml}$ alkaline phosphatase-conjugated streptavidin (Jackson ImmunoResearch Laboratories), in PBST supplemented with $2 \%$ BSA. The assay was developed with the Vector AP substrate kit (Vector Laboratories). The plates were then washed, dried, and analyzed using the CTL ImmunoSpot scanner and software (Cellular Technology).

\section{DC immunization}

Bone marrow (BM)-derived DC of $L M P 7+M E C L$-1-deficient mice were expanded for 5 days with GM-CSF $(20 \mathrm{ng} / \mathrm{ml}$, derived from the culture supernatant of the cell line X63.Ag), activated overnight with $10 \mathrm{ng} / \mathrm{ml}$ LPS (Sigma-Aldrich) and then pulsed for $5 \mathrm{~h}$ with $10 \mu \mathrm{M}$ synthetic $\mathrm{E} 1 \mathrm{~A}_{234-243}, \mathrm{E}_{1 \mathrm{~B}}{ }_{192-200}$ or $\mathrm{OVA}_{257-264}$. Peptide-pulsed DCs were mixed and $L M P 7+M E C L-1$-deficient and $\mathrm{B} 6$ control mice were injected i.p. with $3 \times 10^{6}$ DCs in $100 \mu$ l of PBS. Seven days after immunization, spleens were harvested, and percentages of CD8 T cells reacting to the $\mathrm{E}_{1} \mathrm{~A}_{234-243}$,

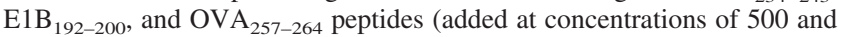
$1 \mathrm{nM}$ ) were determined by intracellular IFN- $\gamma$ staining.

\section{DC infection experiments}

$\mathrm{BM}$ cells of $L M P 7+M E C L-1$-deficient and control B6 mice were cultured for 5 days with GM-CSF. CD11c cells $\left(1 \times 10^{6}\right)$ were plated in the wells of 24-well plates in RPMI 1640 medium without regular antibiotics but supplemented with $5 \mu \mathrm{g} / \mathrm{ml}$ erythromycin or $250 \mu \mathrm{g} / \mathrm{ml}$ spectinomycin and then infected for $1 \mathrm{~h}$ with rLM-OVA or rLM-E1, at multiplicities of infection of 1:250 and 1:100, respectively. After infection, the medium was replaced by RPMI 1640 medium without regular antibiotics but containing gentamicin. At different time intervals, intracellular bacterial growth and MHC class I cell surface trafficking were blocked by addition of tetracycline $(20 \mu \mathrm{g} / \mathrm{ml})$ and monensin $(10 \mu \mathrm{M})$ to the culture medium. To detect processing and MHC class I presentation of bacterially secreted Ags, infected DCs and uninfected control DCs loaded with or without synthetic peptide were incubated overnight with $1 \times 10^{6} \mathrm{OVA}_{257-264^{-}}, \mathrm{E}_{1 \mathrm{~A}} \mathrm{~A}_{234-243^{-}}$,

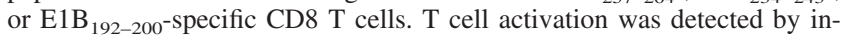
tracellular IFN- $\gamma$ staining. This method has been shown before to reliably quantify peptide-MHC class I complexes presented on infected cells (11).

\section{Splenocyte transfer}

To deplete T cells, $L M P 7+M E C L-1$-deficient mice were injected i.p. with $200 \mu \mathrm{g}$ of GK1.5 (anti-CD4) and $150 \mu \mathrm{g}$ of 3.155 (anti-CD8) in $300 \mu \mathrm{lof}$ PBS, on two consecutive days. At day 3 , the mice were infected with $5 \times$ $10^{3}$ rLM-E1. After $36 \mathrm{~h}$, spleens were harvested, pressed through a cell strainer, washed with PBS, filtered twice (40- $\mu \mathrm{m}$ pore size filter), and then injected i.v. into naive $L M P 7+M E C L$-1-deficient mice (1.5 donors to 1 recipient). Injected splenocytes contained $<0.7 \% \mathrm{CD}^{+}$cells. A second group of naive $L M P 7+M E C L$-1-deficient control mice received $5 \times 10^{3}$ rLM-E1 i.v. Both mouse groups were injected s.c. with $1 \mathrm{mg}$ of ampicillin in $100 \mu \mathrm{l}$ of PBS at the time point of rLM-E1 or splenocyte injection and received ampicillin through the drinking water $(2 \mathrm{mg} / \mathrm{ml})$, for 3 days. Seven days after infection, spleens were harvested and assayed for the presence of E1A- and E1B-specific CD8 T cells by IFN- $\gamma$ ELISPOT.

\section{Results}

CD8 $T$ cell responses to the LM-secreted p60E1 Ag

To examine the mechanistic aspects underlying the preferential targeting of immunoproteasome-generated antigenic peptides, we modified L. monocytogenes to secrete a model Ag (p60E1) that is degraded by host cell proteasomes (12) and encompasses two wellstudied model epitopes derived from the adenovirus type 5 early $1 \mathrm{~A}$ and $\mathrm{B}$ regions (Fig. 1A) $(7,10)$. The two epitopes form stable complexes with the MHC class I H-2 $\mathrm{D}^{\mathrm{b}}$ molecule $\left(t_{1 / 2} \mathrm{H} 2-\mathrm{D}^{\mathrm{b}} /\right.$ E1Ap complex: $6.3 \mathrm{~h} ; t_{1 / 2} \mathrm{H} 2-\mathrm{D}^{\mathrm{b}} / \mathrm{E} 1 \mathrm{Bp}$ complex: $6.1 \mathrm{~h}$; Table I) and can evoke vigorous CD8 $\mathrm{T}$ cell responses. Their immunodominance hierarchy alternates, depending on vector context $(13,14)$. 


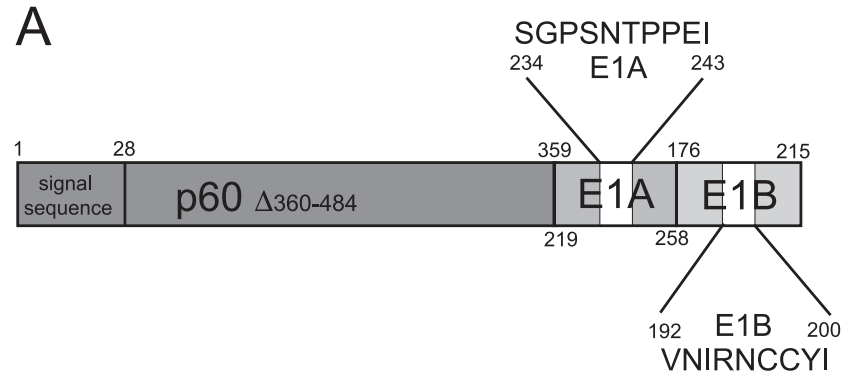

B

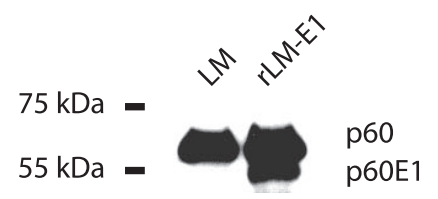

C

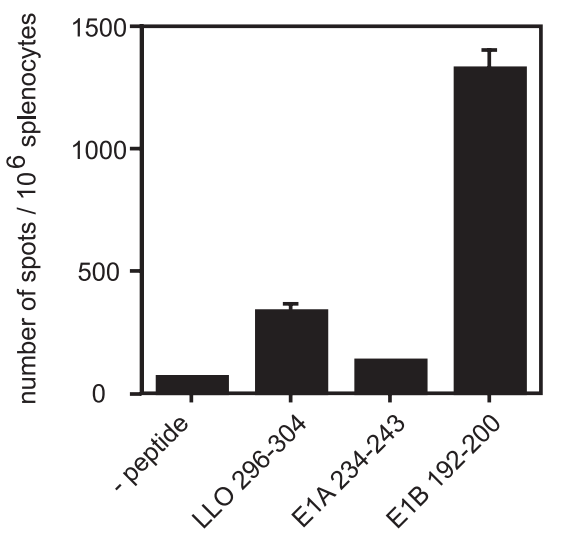

FIGURE 1. Construction and characterization of rLM-E1. A, Sequences encoding the LM p60 promoter and p60 residues 1-360 were amplified and fused in frame to the $\mathrm{E} 1$ sequences $\mathrm{E} 1 \mathrm{~A}_{219-258}$ and $\mathrm{E} 1 \mathrm{~B}_{176-215}$ with the addition of a stop codon. Obtained p60-E1 construct was cloned into the pAT29 shuttle vector and introduced into L. monocytogenes (LM) strain 10403S. Approximately $75 \%$ of rLM-E1 retained pAT29p60E1 during $24 \mathrm{~h}$ of passage through B6 mice, indicating the stable expression of this plasmid. $B$, rLM-E1 secreted p60E1 into the medium, as detected by Western blot analysis on culture supernatant with an anti-p60 serum. $C$, rLM-E1 infection induced

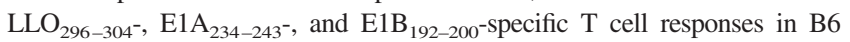
mice, as measured by IFN- $\gamma$ ELISPOT. Bars, means $(n=5) \pm$ SEM.

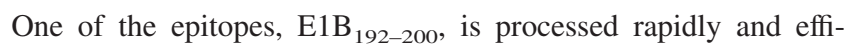
ciently by immunoproteasomes, whereas constitutive proteasomes use the cleavage sites flanking this epitope with relatively low frequency $(7,10)$. The second epitope, $\mathrm{E} \mathrm{A}_{234-243}$, is processed efficiently in both the absence and presence of the immunoproteasome subunits (10). In p60E1, the two epitopes are surrounded by their natural flanking sequences (Fig. $1 A$ ) to conserve the natural epitope-surrounding proteasomal cleavage sites.

The constructed Listeria strain rLM-E1 (Fig. 1A) secreted the heterologous p60E1 protein (Fig. $1 B$ ). To determine whether rLM-E1 elicited E1-specific CD8 T cell responses, B6 mice were inoculated i.v. with a sublethal bacterial dose and responses in the spleen were quantified 7 days later (Fig. 1C). rLM-E1-infected mice responded most vigorously to E1B $_{192-200}$, whereas $\mathrm{E}_{1 \mathrm{~A}} \mathrm{~A}_{234-243}$ and a $L$. monocytogenes-derived epitope $\left(\mathrm{LLO}_{296-304}\right)$ elicited smaller CD8 T cell responses. Uninfected mice failed to react to any of these epitopes (not shown). Thus, $\mathrm{E}_{1 \mathrm{~B}}{ }_{192-200}$ dominates over $\mathrm{E}_{1} \mathrm{~A}_{234-243}$ when processed from p60E1.
Table I. Stability of MHC class I-rLM peptide complexes

\begin{tabular}{cc}
\hline \hline MHC-Peptide Complex & $t_{1 / 2}(\mathrm{~h})$ \\
\hline $\mathrm{H}^{2}-\mathrm{D}^{\mathrm{b}} / \mathrm{E} 1 \mathrm{~B}_{192-200}$ & $6.1^{a}$ \\
$\mathrm{H} 2-\mathrm{D}^{\mathrm{b}} / \mathrm{E}^{\mathrm{A}} \mathrm{A}_{234-243}$ & 6.3 \\
$\mathrm{H} 2-\mathrm{K}^{\mathrm{b}} / \mathrm{ova}_{257-264}$ & 5.1 \\
\hline
\end{tabular}

${ }^{a}$ Half-lives of MHC-peptide complexes on the surface of RMA-S cells.

\section{rLM-E1-infected immunosubunit-deficient mice fail to respond to $E 1 B_{192-200}$}

To examine whether immunoproteasomes played a role in the priming of E1B-specific CD8 T cells, we infected LMP7+ $M E C L-1$ double-gene-deficient B6 mice (9) and control mice with sublethal doses $\left(0.1 \times \mathrm{LD}_{50}\right)$ of rLM-E1 or rLM-OVA (8), which secretes truncated OVA encompassing the immunoproteasome-independent (15) $\mathrm{OVA}_{257-264}$ epitope. Quantitation of $\mathrm{CD} 8 \mathrm{~T}$ cell responses to the different model epitopes at day 7 after infection (Fig. 2A) showed that rLM-E1-infected $L M P 7+M E C L-1$-deficient mice failed to respond to the immunoproteasome-dependent E1B epitope, upon both primary and recall infection, whereas $\mathrm{E}_{1 \mathrm{~B}_{192-200}}$ was the predominant target of the E1-specific CD8 T cell response in rLM-E1-infected control B6 mice. Frequencies of CD8 T cells responding to the p60E1-derived E1A control epitope were similar between the two mouse groups (Fig. 2A). Moreover, both B6 control and gene-deficient mice responded vigorously to rLM-OVA-derived $\mathrm{OVA}_{257-264}$ (Fig. 2A). Thus, mice lacking $L M P 7+M E C L-1$ were unable to respond to p60E1-derived $\mathrm{E}_{1 B_{192-200}}$ but mounted normal responses to the p60E1-derived $\mathrm{E}_{1} \mathrm{~A}_{234-243}$ and OVA-derived $\mathrm{OVA}_{257-264}$ control epitopes.

To test whether the absence of $\mathrm{E}_{1 \mathrm{~B}_{192-200}}$-specific responses in rLM-E1-infected $L M P 7+M E C L-1$-deficient mice could be explained by defects in the TCR repertoire, mice were immunized with GM-CSF-expanded BM-derived DCs pulsed with synthetic E1B $_{192-200}$. Both $L M P 7+M E C L-1$-deficient and control mice mounted $\mathrm{E}_{1 B_{192-200}}$-specific responses (Fig. $2 B$ ). Most of the responding CD8 T cells reacted to both high (500 nM) and low (1 $\mathrm{nM}$ ) concentrations of synthetic $\mathrm{E} 1 \mathrm{~B}_{192-200}$ (Fig. 2B), indicting that both gene-deficient and control mice possess naive $\mathrm{T}$ cells with high affinity for the $\mathrm{D}^{\mathrm{b}} / \mathrm{E}_{1} \mathrm{~B}_{192-200}$ complex. Thus, although we cannot exclude that the E1B-specific $\mathrm{T}$ cell repertoire may differ between control and gene-deficient mice, our data show that the defective priming of E1B-specific responses in rLM-E1-infected $L M P 7+M E C L-1$-deficient mice cannot be explained by a lack of $\mathrm{T}$ cell precursors.

\section{Delayed presentation of E1B ${ }_{192-200}$ by rLM-p60E1-infected, immunosubunit-deficient DCs}

To further explore the relationship between Ag-processing efficiency and CD8 $\mathrm{T}$ cell priming, we determined whether the absence of $L M P 7+M E C L-1$ altered the presentation of the different model epitopes by GM-CSF-expanded BM DC infected with rLM-E1 or rLM-OVA (Fig. 3B). Bacterial protein synthesis and MHC class I cell surface transport were stopped at different time points after infection by the addition of tetracycline and monensin, respectively, and epitope presentation was detected using established CD8 T cell lines that displayed similar sensitivities for their respective peptide ligands (Fig. 3A). These analyses of epitope presentation (Fig. 3B) revealed that rLM-E1-infected DC of $L M P 7+M E C L$-1-deficient and control B6 mice presented the E1A epitope with similar kinetics; i.e., E1 $\mathrm{A}_{234-243}$ slowly accumulated on the surface of both types of DCs. In contrast, the amounts of 
A

$$
\begin{aligned}
& \text { primary } \\
& \text { infection }
\end{aligned}
$$

recall

infection

\section{rLM-E1}
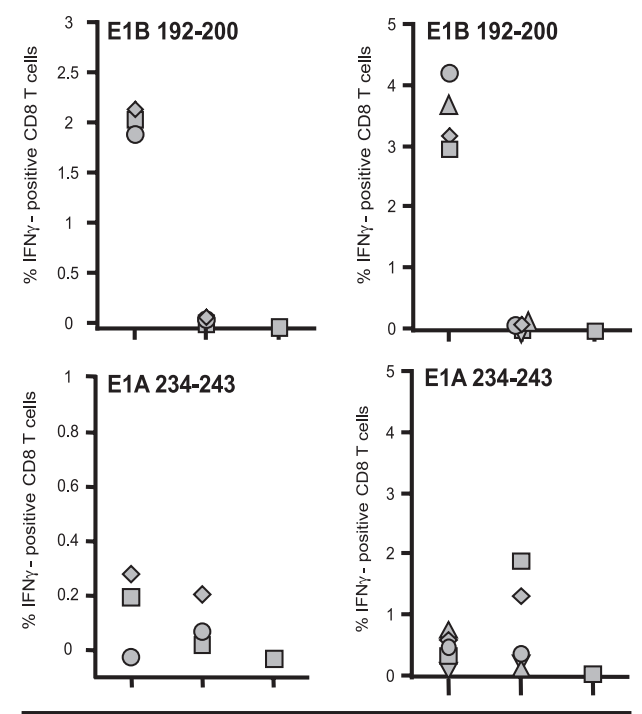

\section{rLM-ova}
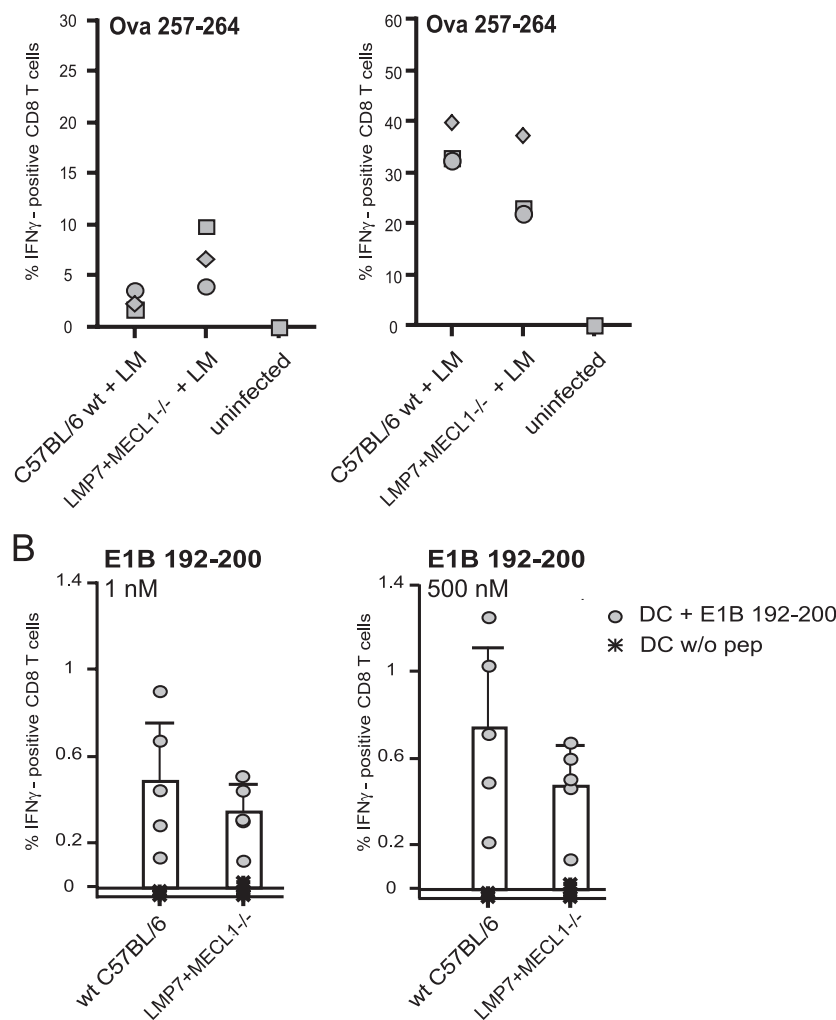

FIGURE 2. Lack of $\mathrm{E}_{1 \mathrm{~B}}{ }_{192-200}$ responses in $L M P 7+M E C L$-1-deficient mice. $L M P 7+M E C L-1$ gene-deficient and control $\mathrm{B} 6$ mice were infected i.v. with primary doses of $5 \times 10^{3}$ rLM-E1 or $1 \times 10^{5}$ rLM-OVA, or secondary doses of $5 \times 10^{5}$ and $1 \times 10^{7}$ bacteria, respectively $(A)$, or

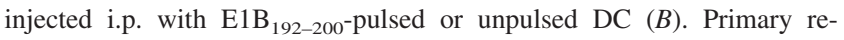
sponses to the indicated peptides were measured on day 7 ( $A$ and $B)$, recall responses $(A)$ on day 5 after rLM or DC injection by intracellular IFN- $\gamma$ staining. Values are mean results for individual mice $(A$ and $B) \pm \operatorname{SEM}(B)$. Similar results were obtained in five independent experiments. LM, $L$. monocytogenes;wt, wild type; w/o pep., without peptide.

E1B peptide increased rapidly on B6 DCs (first detectable after $3 \mathrm{~h}$ of infection with maximal $\mathrm{T}$ cell activation reached after $5 \mathrm{~h}$ (Fig. $3 B$ ) but not on $L M P 7+M E C L-1$-deficient DC, which needed a longer period of time to accumulate detectable amounts. The control rLM-OVA-derived $\mathrm{OVA}_{257-264}$ epitope was rapidly presented by both $\mathrm{B} 6$ and gene-deficient DC (Fig. $3 B$ ). Comparing the results of the kinetic analyses of epitope presentation with the sizes of epitope-specific CD8 T cell responses in Fig. 2, we find a remarkable correlation between rates of epitope presentation and immunogenicity of the respective model epitopes in $\mathrm{B} 6(\mathrm{E} 1 \mathrm{~B}>\mathrm{E} 1 \mathrm{~A})$ and $L M P 7+M E C L$-1-deficient mice (E1A $>$ E1B).

\section{Kinetics of presentation determine the immunogenicity of E1B $192-200$}

Based on our data thus far, the inability of infected $L M P 7+M E C L$ 1-deficient mice to respond to p60E1-derived E1B ${ }_{192-200}$ may be explained by the delayed processing and presentation of this epitope in the absence of immunoproteasomes. Alternatively, it is possible that the epitope quantities presented on DC of these mice are insufficient to activate naive $\mathrm{E}_{1 \mathrm{~B}_{192-200}}$-specific CD8 T cells. The initiation of both primary and recall $\mathrm{CD} 8 \mathrm{~T}$ cell responses requires $\mathrm{Ag}$ presentation by $\mathrm{DC}(16,17)$. To examine first whether DCs of infected mice present E1B in vivo, $L M P 7+M E C L-1$-deficient and control B6 mice were immunized with E1B ${ }_{192-200^{-}}$ pulsed cells. After 28 days, the immune mice were challenged with rLM-E1 and E1B-specific CD8 T cell responses were quantified in the spleens at day 5 after infection. rLM-E1 induced vigorous E1B-specific CD8 $\mathrm{T}$ cell responses in both control and LMP7+ $M E C L$-1-deficient $\mathrm{DC}+\mathrm{E}_{1 \mathrm{~B}}{ }_{192-200}$ immunized mice (Fig. 4A) whereas, at this time point, no or small E1B-specific CD8 T cell responses were detectable in the spleens of $L M P 7+M E C L-1$-deficient and control B6 mice that had been immunized with nonpeptide-pulsed DCs. These findings indicate that $\mathrm{E} \mathrm{B}_{192-200}$ is processed from p60E1 and presented on DCs of rLM-E1infected mice.

Previous studies have shown that the first $24 \mathrm{~h}$ of infection are crucial for the priming of L. monocytogenes-specific CD8 T cells (18). To discern whether the quantities or kinetics of E1B $\mathrm{B}_{192-200}$ presentation explain the inability of rLM-E1-infected LMP7+ $M E C L$-1-deficient mice to mount $\mathrm{E}_{1 \mathrm{~B}_{192-200}}$-specific responses, we determined whether pAPC of infected $L M P 7+M E C L-1$ deficient mice that present the rLM-E1-derived epitopes at steady state levels are able to prime E1B-specific CD8 $\mathrm{T}$ cell responses in naive gene-deficient mice. $L M P 7+M E C L$-1-deficient mice were depleted of CD4 and CD8 T cells to prevent the formation of clusters between Ag-presenting pAPC and T cells and were then infected with rLM-E1. After $36 \mathrm{~h}$, splenocytes were harvested and transferred into naive $L M P 7+M E C L$-1-deficient mice. The recipient mice were simultaneously treated with ampicillin, to avoid infection with donor-derived bacteria. Quantitation of CD8 T cell responses seven days later by IFN- $\gamma$ ELISPOT (Fig. $4 B$ ) revealed significant numbers of E1B-specific CD8 T cells in the spleens of the recipient mice, which equaled the numbers of E1A-specific CD8 T cells. No E1-specific responses were detected in control ampicillin-treated $L M P 7+M E C L$-1-deficient mice that, instead of receiving splenocytes, had been infected with rLM-E1, implying that the E1-specific responses in splenocyte recipient mice were unlikely to be evoked by surviving, donor-derived rLM-E1. From these data, we infer that the quantities of $\mathrm{E}_{1 \mathrm{~B}_{192-200}}$ processed and presented by pAPC of infected $L M P 7+M E C L-1$ deficient mice are sufficient to prime naive CD8 T cells and, furthermore, that the two p60E1-derived epitopes are codominant when offered in a preprocessed form. Our results therefore strongly suggest that the kinetics of epitope appearance on single pAPC rather than solely epitope quantity may explain for the immunogenicity or lack of certain antigenic peptides. 


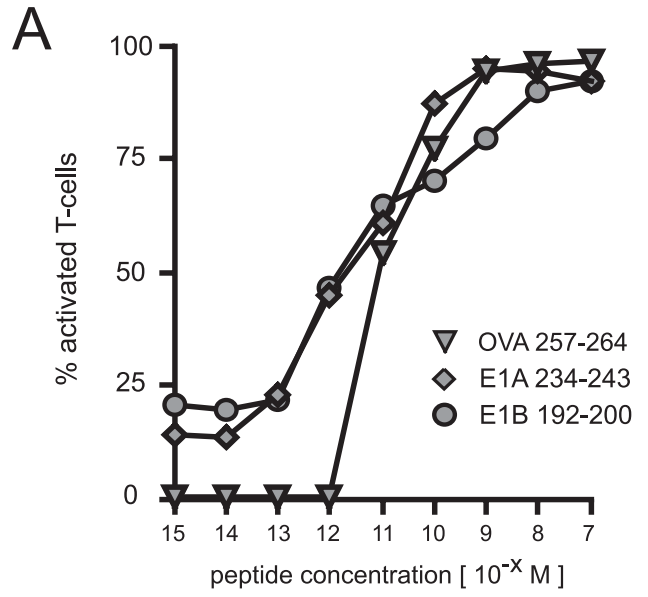

B rLM-E1
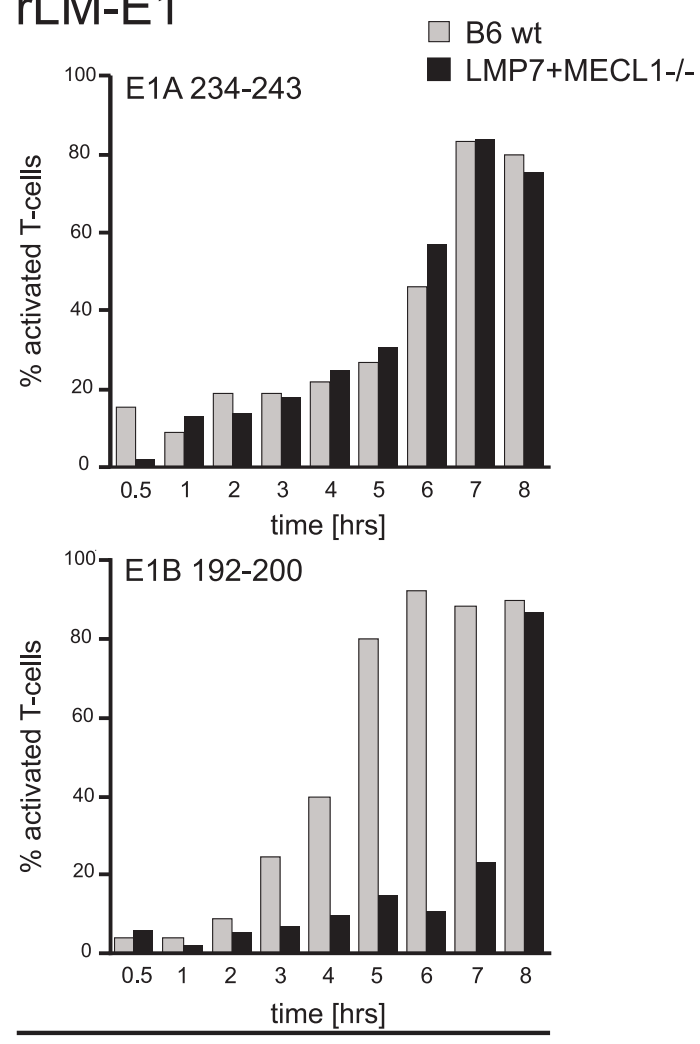

rLM-ova

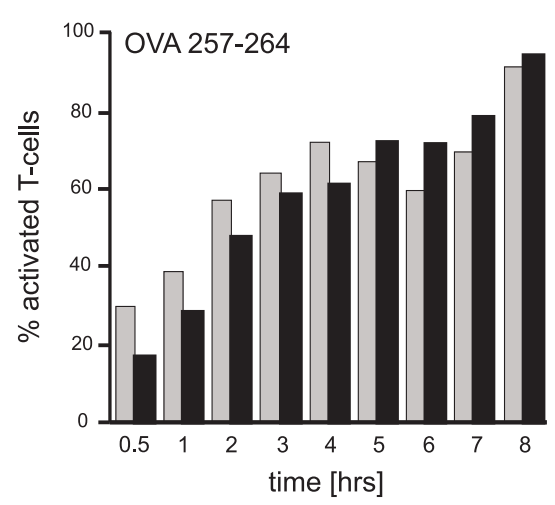

FIGURE 3. Delayed $\mathrm{E}_{1} \mathrm{~B}_{192-200}$ presentation on infected $L M P 7+M E C L$ 1-deficient BM-DC. A, $\mathrm{OVA}_{257-264^{-}}, \mathrm{E} 1 \mathrm{~A}_{234-243^{-}}$, and $\mathrm{E} 1 \mathrm{~B}_{192-200^{-}}$-specific CD8 T cells incubated with dilutions of synthetic peptides, loaded on ANA-1 cells, recognize their respective ligands with comparable sensitivities. T cell activation was measured by intracellular IFN- $\gamma$ staining. $B$, Presentation
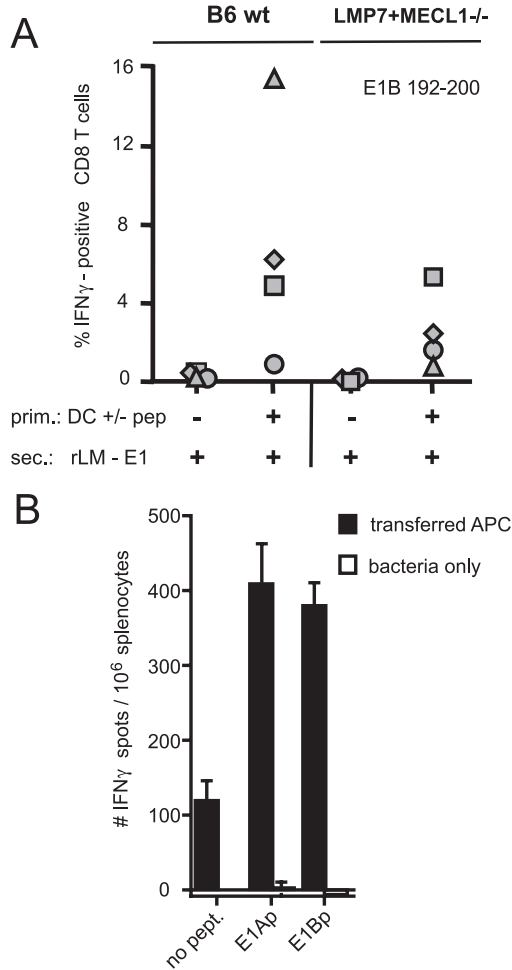

FIGURE 4. In vivo presentation of $\mathrm{E}^{1} \mathrm{~B}_{192-200}$ in $L M P 7+M E C L-1$-deficient mice. $A, \mathrm{E} \mathrm{B}_{192-200}$-specific CD8 $\mathrm{T}$ cells, primed by immunization with $\mathrm{E}_{1 \mathrm{~B}_{192-200}}$-pulsed DC, expanded upon reinfection with rLM-E1. $B$, Splenocytes of T cell-depleted $L M P 7+M E C L-1$ gene-deficient mice, infected for $36 \mathrm{~h}$ with rLM-E1-, primed $\mathrm{E}_{1} \mathrm{~B}_{192-200^{-}}$, and $\mathrm{E} 1 \mathrm{~A}_{234-243}$-specific CD8 $\mathrm{T}$ cells in naive LMP7+MECL-1 $1^{-1-}$ mice, as measured by IFN- $\gamma$ ELISPOT. Similar results were obtained in three independent experiments. wt, Wild type; prim., primary; pept., peptide; sec., secondary; bars, SEM.

\section{Discussion}

Taken together, our data demonstrate a new mechanism that controls CD8 $\mathrm{T}$ cell priming on the level of Ag processing. Incorporation of the IFN- $\gamma$-inducible subunits into proteasomes leads to a more frequent cleavage of specific peptide bonds and thereby 1) to a faster appearance of certain peptides on the pAPC surface and 2) to enhanced peptide quantities. Different from the general assumption (19), we here show that the effects of immunoproteasomes on epitope presentation kinetics are more important than their effects on overall epitope quantity.

How can one explain our finding that rates of processing influence the immunogenicity of CD8 T cell epitopes? Multiple studies have indicated that $\mathrm{Ag}$ presentation by DCs is highly regulated. Thus, their capacity to capture, process, and present Ags, including those presented by MHC class I molecules, depends on the maturation status of the DC. Hence, it is possible that DCs have a limited time window only to process and present $\mathrm{Ag}$ and to engage in stable, long-lasting and probably monogamous interactions (20) with naive CD8 $\mathrm{T}$ cells that scan the draining lymph nodes for pAPCs presenting the appropriate peptide. In addition, previous

kinetics of p60E1-derived E1B ${ }_{192-200}$ and E1 $\mathrm{A}_{234-243}$ and of OVA-derived $\mathrm{OVA}_{257-264}$ on infected BM-DC. At different time points after infection with rLM-E1 or rLM-OVA, intracellular bacterial growth and MHC class I cell surface trafficking were blocked with tetracycline and monensin. Presentation of the different antigenic peptides was detected with the CD8 $\mathrm{T}$ cells shown in $A$. Results are representative of three experiments. wt, Wild type. 
studies have shown that the number of pAPCs presenting pathogen-derived peptides in the lymph node is only small and that these pAPCs are short-lived (21). Therefore, it is tempting to speculate that the availability of pAPC presenting pathogen-derived Ags represents the bottle neck by which the immunodominance hierarchy of the elicited CD8 T cell response is determined. An epitope that is presented earlier on pAPCs has a greater chance of binding naive CD8 T cells than an epitope that is presented later. Once a stable interaction is formed, it probably is less likely for the pAPC to form additional stable interactions with other naive $\mathrm{T}$ cells. Therefore, an epitope that is presented early on the pAPC would in this way prevent naive CD8 T cells specific for epitopes presented at later time points from being primed, leading to the previously (2) postulated immunodomination of in this case early presented epitopes. Thus, the MHC-encoded immunoproteasome subunits could use such a mechanism to convert cryptic epitopes into dominant epitopes by accelerating the generation and, thereby, the presentation of specific peptides on pAPCs. In good agreement with this model, Willis et al. (6) recently demonstrated that competition between $\mathrm{T}$ cells of different specificities for interaction with the same Ag-presenting DC is a very early event in T cell activation, which occurs within the first $5 \mathrm{~h}$ of immunization and affects the number of $\mathrm{T}$ cells entering the response.

Our observation that the time point of epitope appearance on pAPCs plays an important role in immunogenicity is in line with findings by others that emphasize that the events occurring very early after infection are of crucial importance for the priming of $\mathrm{T}$ cell responses $(6,18,22)$. For example, Pamer and coworkers (18) found that the first $24 \mathrm{~h}$ of infection with $L$. monocytogenes are decisive for the initiation of Ag-specific CD8 T cell responses. Furthermore, immunologists studying the fine specificity of CD8 T cell responses to several murine and human viral pathogens have shown that CD8 T cells frequently respond to peptides that derive from early expressed proteins $(23,24)$. Nevertheless, the mechanisms underlying the preferential targeting of early expressed vs rapidly processed epitopes may differ. In case of viral infections, the individual epitopes localize on different viral Ags that are expressed at different time points after infection and probably presented by different pAPCs. In contrast, the two E1 epitopes derive from the same $\mathrm{Ag}$ and thus are processed by the same pAPC but with differing efficiencies and therefore presented at differing time points after infection.

Many studies aimed to design vaccines that induce protective CD8 T cell-mediated immunity use vector organisms to introduce the relevant Ags. Our finding that rates of epitope generation from vector-encoded Ags influence the immunogenicity of CD8 T cell epitopes implies that such vaccines may be more effective when rapid processing of an included epitope is guaranteed. Thus, future studies identifying sequences that allow rapid proteasome-mediated epitope liberation may support the development of more efficient $\mathrm{T}$ cell-based vaccines.

\section{Disclosures}

The authors have no financial conflict of interest.

\section{References}

1. Yewdell, J. W. 2006. Confronting complexity: real-world immunodominance in antiviral CD8 ${ }^{+} \mathrm{T}$ cell responses. Immunity 25: 533-543.
2. Yewdell, J. W., and J. R. Bennink. 1999. Immunodominance in major histocompatibility complex class I-restricted T lymphocyte responses. Annu. Rev. Immunol. 17: 51-88.

3. Khan, S., M. van den Broek, K. Schwarz, R. de Giuli, P. A. Diener, and M. Groettrup. 2001. Immunoproteasomes largely replace constitutive proteasomes during an antiviral and antibacterial immune response in the liver. $J$. Immunol. 167: 6859-6868.

4. Sijts, A., D. Zaiss, and P. M. Kloetzel. 2001. The role of the ubiquitin-proteasome pathway in MHC class I antigen processing: implications for vaccine design. Curr. Mol. Med. 1: 665-676.

5. Kloetzel, P. M. 2001. Antigen processing by the proteasome. Nat. Rev. Mol. Cell Biol. 2: $179-187$.

6. Willis, R. A., J. W. Kappler, and P. C. Marrack. 2006. CD8 T cell competition for dendritic cells in vivo is an early event in activation. Proc. Natl. Acad. Sci. USA 103: 12063-12068.

7. Sijts, A. J., S. Standera, R. E. Toes, T. Ruppert, N. J. Beekman, P. A. van Veelen, F. A. Ossendorp, C. J. M. Melief, and P. M. Kloetzel. 2000. MHC class I antigen processing of an adenovirus CTL epitope is linked to the levels of immunoproteasomes in infected cells. J. Immunol. 164: 4500-4506.

8. Foulds, K. E., L. A. Zenewicz, D. J. Shedlock, J. Jiang, A. E. Troy, and H. Shen. 2002. Cutting edge: CD4 and CD8 T cells are intrinsically different in their proliferative responses. J. Immunol. 168: 1528-1532.

9. Caudill, C. M., K. Jayarapu, L. Elenich, J. J. Monaco, R. A. Colbert, and T. A. Griffin. 2006. T cells lacking immunoproteasome subunits MECL-1 and LMP7 hyperproliferate in response to polyclonal mitogens. J. Immunol. 176: 4075-4082.

10. Zaiss, D. M., S. Standera, P. M. Kloetzel, and A. J. Sijts. 2002. PI31 is a modulator of proteasome formation and antigen processing. Proc. Natl. Acad. Sci. USA 99: 14344-14349.

11. Anton, L. C., J. W. Yewdell, and J. R. Bennink. 1997. MHC class I-associated peptides produced from endogenous gene products with vastly different efficiencies. J. Immunol. 158: 2535-2542.

12. Sijts, A. J., I. Pilip, and E. G. Pamer. 1997. The Listeria monocytogenes-secreted p60 protein is an N-end rule substrate in the cytosol of infected cells: implications for major histocompatibility complex class I antigen processing of bacterial proteins. J. Biol. Chem. 272: 19261-19268.

13. Rawle, F. C., B. B. Knowles, R. P. Ricciardi, V. Brahmacheri, P. DuerksenHughes, W. S. Wold, and L. R. Gooding. 1991. Specificity of the mouse cytotoxic T lymphocyte response to adenovirus 5 . E1A is immunodominant in $\mathrm{H}-2^{b}$, but not in $\mathrm{H}-2^{d}$ or H-2 ${ }^{k}$ mice. J. Immunol. 146: 3977-3984.

14. Toes, R. E., R. Offringa, R. J. Blom, R. M. Brandt, A. J. van der Eb, C. J. Melief, and W. M. Kast. 1995. An adenovirus type 5 early region 1B-encoded CTL epitope-mediating tumor eradication by CTL clones is down-modulated by an activated ras oncogene. J. Immunol. 154: 3396-3405.

15. Niedermann, G., R. Grimm, E. Geier, M. Maurer, C. Realini, C. Gartmann, J. Soll, S. Omura, M. C. Rechsteiner, W. Baumeister, and K. Eichmann. 1997. Potential immunocompetence of proteolytic fragments produced by proteasomes before evolution of the vertebrate immune system. J. Exp. Med. 186: 209-220.

16. Jung, S., D. Unutmaz, P. Wong, G. Sano, K. De los Santos, T. Sparwasser, S. Wu, S. Vuthoori, K. Ko, F. Zavala, et al. 2002. In vivo depletion of CD $11 c^{+}$dendritic cells abrogates priming of $\mathrm{CD} 8^{+} \mathrm{T}$ cells by exogenous cell-associated antigens. Immunity 17: 211-220

17. Zammit, D. J., L. S. Cauley, Q. M. Pham, and L. Lefrancois. 2005. Dendritic cells maximize the memory CD8 T cell response to infection. Immunity 22: 561-570.

18. Mercado, R., S. Vijh, S. E. Allen, K. Kerksiek, I. M. Pilip, and E. G. Pamer. 2000. Early programming of $\mathrm{T}$ cell populations responding to bacterial infection. J. Immunol. 165: 6833-6839.

19. Chen, W., C. C. Norbury, Y. Cho, J. W. Yewdell, and J. R. Bennink. 2001. Immunoproteasomes shape immunodominance hierarchies of antiviral CD8 ${ }^{+} \mathrm{T}$ cells at the levels of T cell repertoire and presentation of viral antigens. J. Exp. Med. 193: 1319-1326.

20. Bousso, P., and E. Robey. 2003. Dynamics of $\mathrm{CD} 8^{+} \mathrm{T}$ cell priming by dendritic cells in intact lymph nodes. Nat. Immunol. 4: 579-585.

21. Norbury, C. C., D. Malide, J. S. Gibbs, J. R. Bennink, and J. W. Yewdell. 2002. Visualizing priming of virus-specific $\mathrm{CD}^{+} \mathrm{T}$ cells by infected dendritic cells in vivo. Nat. Immunol. 3: 265-271.

22. Itano, A. A., S. J. McSorley, R. L. Reinhardt, B. D. Ehst, E. Ingulli, A. Y. Rudensky, and M. K. Jenkins. 2003. Distinct dendritic cell populations sequentially present antigen to CD4 T cells and stimulate different aspects of cell-mediated immunity. Immunity 19: 47-57.

23. Steven, N. M., N. E. Annels, A. Kumar, A. M. Leese, M. G. Kurilla, L. Frappier, and A. Rickinson. 1997. Immediate early and early lytic cycle proteins are frequent targets of the Epstein-Barr virus-induced cytotoxic T cell response. J. Exp. Med. 185: 1605-1617.

24. Probst, H. C., K. Tschannen, A. Gallimore, M. Martinic, M. Basler, T. Dumrese, E. Jones, and M. F. van den Broek. 2003. Immunodominance of an antiviral cytotoxic $\mathrm{T}$ cell response is shaped by the kinetics of viral protein expression. J. Immunol. 171: 5415-5422. 